В. Ц. Лыгденов, А. В. Номоев, В. В. Сызранцев. Влияние нанодисперсного порошка диоксида кремния марки Таркосил Т-20 на прочностные характеристики...

УДК 532.135

DOI: $18.101 / 2306-2363-2019-2-3-7-11$

\title{
ВЛИЯНИЕ НАНОДИСПЕРСНОГО ПОРОШКА ДИОКСИДА КРЕМНИЯ МАРКИ ТАРКОСИЛ Т-20 НА ПРОЧНОСТНЫЕ ХАРАКТЕРИСТИКИ ЛАКОКРАСОЧНОГО ПОКРЫТИЯ ИЗ ЭМАЛИ ХВ-16
}

\section{(C) В. Ц. Лыгденов}

Бурятский государственный университет им. Д. Банзарова 67000 , Улан-Удэ, ул. Смолина, 24а

Институт физического материаловедения СО РАН

670031, Улан-Удэ, ул. Сахьяновой, 6

E-mail: Lygdenov65@mail.ru

\section{(C) А. В. Номоев}

доктор физико-математических наук заведующий лабораторией физики композитных материалов Институт физического материаловедения СО РАН 670031, Улан-Удэ, Сахьяновой 6,

E-mail: nomoevav@mail.ru

\section{(C) В. В. Сызранцев}

кандидат физико-математических наук

замдиректора

Институт физического материаловедения СО РАН

670031, Улан-Удэ, ул. Сахьяновой, 6

E-mail: vveliga@mail.ru

Изучено влияние нанодисперсного диоксида кремния на механические характеристики лакокрасочного покрытия из эмали ХВ-16, выявлено оптимальное содержание нанопорошка, при котором покрытие имеет максимальную микротвердость. Обнаружено, что добавки нанопорошка увеличивают микротвердость покрытия почти в полтора раза в сравнении с микротвердостью исходного покрытия. Методом ИКспектроскопии определены межмолекулярные связи в полимерном покрытии и их изменения при модификации эмали нанодисперсным порошком.

Ключевые слова: лакокрасочное покрытие, нанодисперсный порошок, микротвердость, модуль Юнга, диоксид кремния, ИК спектроскопия, эмаль.

\section{Для цитирования:}

Льгденов В. Ц., Номоев А. В., Сызранцев В. В. Влияние нанодисперсного порошка диоксида кремния марки Таркосил Т-20 на прочностные характеристики лакокрасочного покрытия из эмали ХВ-16 // Вестник Бурятского государственного университета. Химия. Физика. 2019. Вып. 2-3. С. 7-12.

В настоящее время в производстве лакокрасочных материалов (ЛКМ) применяются добавки из нанопорошков, при этом их функции многообразны. Нанопорошки используются для интенсификации процесса получения ЛКМ (эмульгаторы, диспергаторы, пеногасители), для оптимизации процесса нанесения (реологические добавки-загустители, ПАВ, агенты розлива и т.д.), а также они вы- 
ступают как модификаторы покрытий из ЛКМ, улучшающие их физикомеханические и прочностные свойства [1-3]. В данном исследовании изучено влияние нанодисперсного диоксида кремния марки на Таркосил со средним размером наночастиц 23 нм, полученный газофазным синтезом на ускорителе электронов, на прочностные характеристики полимерного лакокрасочного покрытия из эмали ХВ-16 на основе перхлорвиниловой и глифталевой смол и определено оптимальное содержание нанопорошка, при котором покрытие имеет максимальное прочностные характеристики. Обнаружено, при концентрации нанопорошка $0,025 \%$ микротвердость покрытия равна 1,4 МПа, что в 1,4 раза выше микротвердости исходного покрытия (рис. 1).

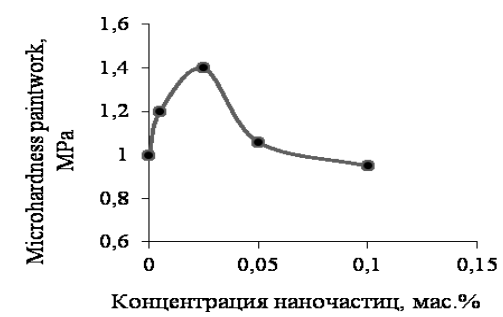

Рис. 1. Микротвердость покрытия из эмали XB-16 в зависимости от концентрации нанопорошка Таркосил Т-20

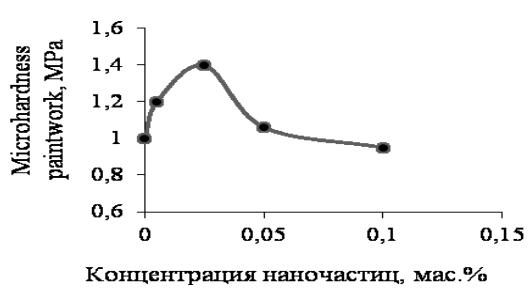

Рис. 2. Зависимость модуля Юнга покрытия из эмали ХВ-16 от концентрации нанопорошка Таркосил Т-20.

Методом атомно-силовой микроскопии АСМ было определено значение модуля Юнга на микроуровне для исходного и модифицированных образцов XВ-16 (рис. 2). Так как для ЛКМ невозможно определить модуль упругости стандартными методами были проведены его измерения на микроуровне методом АСМ в контактном режиме. Использовалась модель Герца, согласно которой, величина прогиба зонда $\mathrm{h}$ зависит от приложенной силы в соответствии с формулой (1), величина прогиба пропорциональна $2 / 3$ степени от сдавливающей силы.

$$
h=F^{\frac{2}{3}}\left(\frac{1}{K^{2}}\left(\frac{1}{r}+\frac{1}{r^{\prime}}\right)\right)^{\frac{1}{3}}
$$

где, $F$ - приложенная сила, $K$ - эффективная жесткость пары «зонд - образец», $r$ - радиус зонда, $r^{\prime}$ - радиус кривизны образца (для плоской поверхности $r$ стремится к бесконечности). Это формула позволяет определить величину прогиба зонда кантилевера в зависимости от приложенной силы и вычислить модуль Юнга по силовым кривым.

Как следует из графика, модуль Юнга принимает максимальное значение в области концентраций нанопорошка 0,025 мас.\%, что коррелирует с данными по микротвердости покрытия XВ-16. Существование максимума на графиках можно объяснить конкуренцией двух взаимоисключающих процессов. Во-первых, снижением трещинообразования по всей толщине покрытия при увеличении содержания нанопорошка в эмали в результате локализации микротрещин на наночастицах диоксида кремния, что приводит повышению микротвердости покрытия. Во-вторых, повышением микронапряжений на границе фаз «наночастица - мо- 
В. Ц. Лыгденов, А. В. Номоев, В. В. Сызранцев. Влияние нанодисперсного порошка диоксида кремния марки Таркосил Т-20 на прочностные характеристики...

лекулы полимера», что снижает микротвердость. Как известно, чем меньше размер частиц наполнителя, тем больше внутренние напряжения [4].

Для количественного описания изменения микроструктуры использовался метод обработки изображений Image Analysis. В этом случае через все структурные элементы поверхности проводили усредненную плоскость и вычисляли основные параметры зерен и их средние значения, а также шероховатость поверхности. Более точным и информативным показателем, по сравнению с линейной $\mathrm{R}_{\mathrm{q}}$, является шероховатость по всей площади поверхности $\mathrm{S}_{\mathrm{q}}$, значения которой представлены на графике (рис. 3).

Исходя из графика на рис. 3 , видно, что $\mathrm{S}_{\mathrm{q}}$ имеет минимальные значения, когда содержание нанопорошка составляет 0,025-0,05 мас.\%. Известно, что у твердых веществ шероховатость поверхности уменьшается с уменьшением размера зерна, поэтому можно сделать вывод о том, что средний размер зерна в модифицированном XВ-16 уменьшается в результате ее модификации по сравнению с исходным образцом. В соответствии с законом Холла-Петча, мелкозернистое состояние твердого вещества приводит к усилению ее механических характеристик, что наблюдается в настоящих исследованиях.

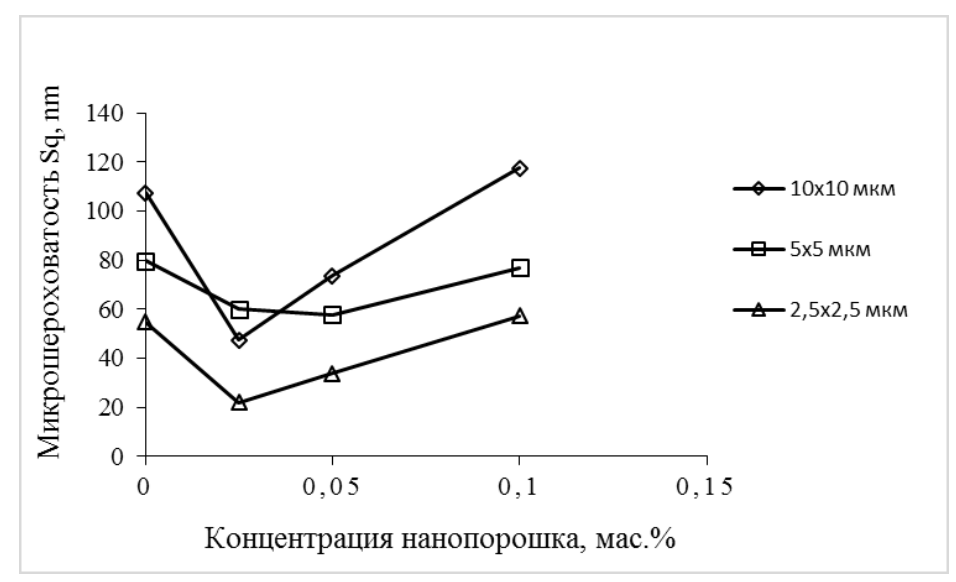

Рис. 3. График зависимости шероховатости по поверхности Sq XB-16 от содержания нанопорошка Таркосил

Для определения изменений химических связей между молекулами полимерной матрицы в результате модифицирования ЛКП нанопорошками диоксида кремния проведено исследование свойств поверхности ЛКП методом ИК спектроскопии (рис. 4). В ИК спектрах всех образцов до и после их модифицирования частицами диоксида кремния не обнаружено появления новых пиков, что означает отсутствие новых функциональных групп с введением наноразмерного диоксида кремния $[5,6]$. 


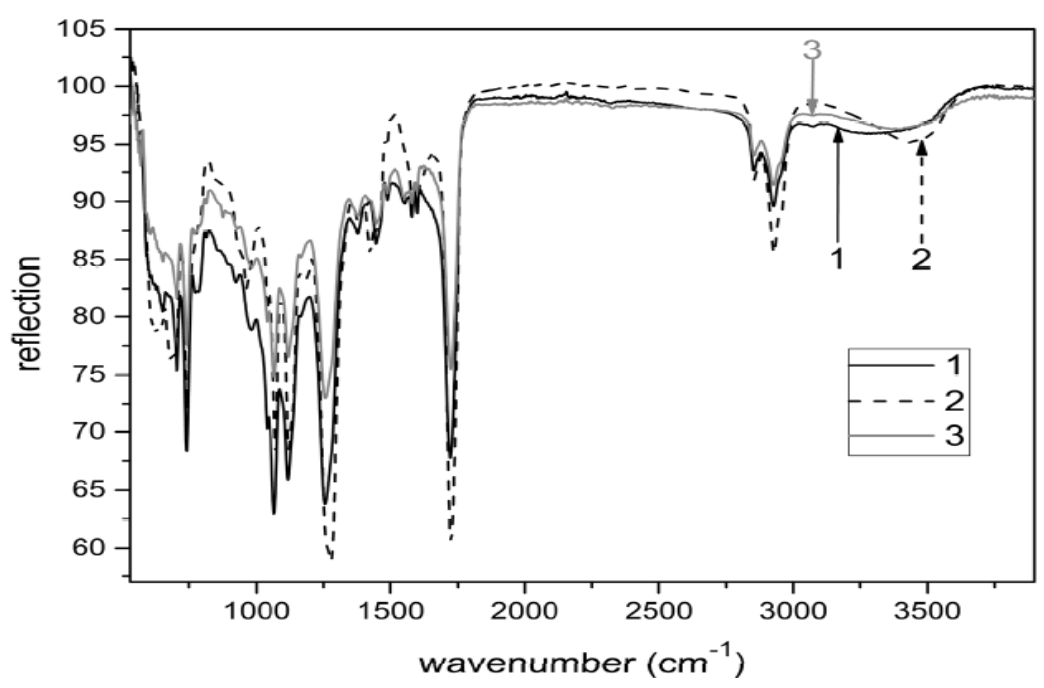

Рис. 4. ИК спектры покрытия из эмали ХВ-16 при различной концентрации нанопорошка: (1- 0 мас.\%, 2 - 0,025 мас.\%, 3 - 0,1 мас.\%).

Но при этом наблюдается повышение интенсивности ИК отражения покрытия при содержании 0,025 масс.\% нанопорошка диоксида кремния, а это указывает на увеличение количества существующих функциональных групп в полимере за счет новых связей данной группы, сформированных наночастицами диоксида кремния и макромолекулами полимера.

Работа выполнена в рамках госзадания Института физического материаловедения СО РАН.

Материалы публикачии частично подготовлены с использованием оборудования ЦКП «Научные приборы» ФГБОУ ВО «Бурятский государственный университет имени Доржи Банзарова».

\section{Литература}

1. Розельфенд И. JL, Рубинштейн Ф. И., Жигалова К. А. Защита металлов от коррозии лакокрасочными покрытиями. - М.: Химия, 1987. — 224 с.

2. Байкина, Л. К., Полубояров В. А. Исследование свойств диацетатцеллюлозных пленок, модифицированных нанодисперсными керамическими частицами // Известия высших учебных заведений: технология легкой промышленности. - 2011. - T. 13, № 3. - C. 11-14.

3. Номоев А. В., Лыгденов В. Ц., Бардаханов С. П. Влияние нанопорошка диоксида кремния на износостойкость лакокрасочного покрытия // Нанотехнологии в строительстве: научный интернет-журнал. — 2010. — № 3. - С. 19-24.

4. Пентин Ю. А., Курамшина Г. М. Основы молекулярной спектроскопии. - М.: Мир, 2008. - $398 \mathrm{c}$.

5. Lever A. B. P. Inorganic Electronic Spectroscopy. 2nd ed., Elsevier: AmsterdamOxford-New York-Tokyo, 1987. - 345 p. 


\section{INFLUENCE OF NANODISPERSED POWDER OF SILICON DIOXIDE OF TARKOSIL T-20 BRAND ON STRENGTH CHARACTERISTICS OF PAINT AND VARNISH COATING FROM ENAMEL XB-16}

\section{TS. Lygdenov}

Research

Buryat State University,

67000, Ulan-Ude, Smolina Str., 24a

Institute of Physical Materials Science SB RAS

670031, Ulan-Ude, Sakhyanovoy, Str., 6

E-mail: Lygdenov65@mail.ru

\section{A. V. Nomoev}

Doctor of Physical and Mathematical Sciences

Head of the laboratory of Physics of Composite Materials

Institute of Physical Materials Science SB RAS

670031, Ulan-Ude, Sakhyanovoy, Str., 6

E-mail: nomoevav@mail.ru

\section{V. Syzrantsev}

Candidate of Physical and Mathematical Sciences

Deputy Director

Institute of Physical Materials Science SB RAS

670031, Ulan-Ude, Sakhyanovoy, Str., 6

E-mail:vveliga@mail.ru

The influence of nanodispersed silicon dioxide on the mechanical characteristics of the paint coating of enamel XB-16 was studied, the optimal content of nanopowder was revealed, at which the coating has a maximum microhardness. It was revealed that nanopowder additives increase the microhardness of the coating almost one and a half times in comparison with the microhardness of the original coating. Intermolecular bonds in the polymer coating and their changes during modification of enamel by nanodisperse powder were determined by IR spectroscopy.

Keywords: paint and varnish coating, nanodisperse powder, microhardness, young modulus, silicon dioxide, IR spectroscopy, enamel. 